\title{
The Need To Incorporate Reflective Practice Into Nursing Education Curriculum In Nigeria
}

\author{
${ }^{1}$ Christie A. Enuku, ${ }^{2}$ Usiwoma Evawoma - Enuku \\ ${ }^{I}$ Christie Akpoigho Enuku Is A Lecturer In The Department Of Nursing Science, University Of Benin, Benin City \\ ${ }^{2}$ Usiwoma Evawoma-Enuku Is A Professor In The Department Of Adult And Non-Formal Education, University \\ Of Benin, Benin City.
}

\begin{abstract}
This paper examines the concept of reflective practice in nursing. It highlights the origin of nursing as it originates from the apprenticeship system in the twentieth century. Following the Second World War, nursing was introduced into higher education and thus the need to fuse practical with theoretical knowledge. It also examines sources of nursing knowledge that is reflected upon. It then examines the difficulties of practicing reflective practice in Nigeria at this point in time. Finally recommendations are made regarding the steps that need to be taken to introduce reflective practice in the nursing curriculum in Nigeria.
\end{abstract}

Keywords: Reflection, Reflective Practice, Nursing knowledge and Skills.

Objective: This paper attempts to discuss the absence of reflective practice in nursing curriculum in Nigeria, identifying the obstacles to its practice at this point in time in Nigeria and suggests the way forward.

\section{Introduction}

Since the inception of health care systems, nursing has been conceptualized as a caring profession which concerned itself with health promotion and the treatment of illness and disease. Health and illness are lived experiences and are accessed through perception, beliefs, skills, practices and expectations. Leira (1994, p.18a) sees caring as "the combination of hand, brain, and heart grounded in the dependent other's lack of capability to care for herself or himself in the salient feature of the caring process". Within transpersonal caring occasions, the brains of caring nurses meld information gathered through their eyes and ears with that from their hands and hearts, as they join with patients. Through these processes nurses recognize and accept the unique worth and eligibility of individual patients (Taylor and Watson, 1989).

Nursing as a profession has been regarded as a profession that concentrated upon action or doing since the 1950s and 1960s which was passed on through the apprenticeship form of education apparent in the twentieth century. It was and still dominated by women. Following the Second World War, with the advent of changes in social circumstances for women, women were able to enter higher education and nurses took this opportunity to examine the nature of nursing and disseminate their findings about nursing and type of knowledge needed for practice.

Thus, from the beginning, nursing has existed within an education system that historically promoted the division of theoretical and practical knowledge which traditionally denies an interrelationship between intellect and emotions (Barnett 1992; Reed and Ground 1997). This philosophical legacy promoted the idea that intellectual knowledge is different from and is superior to practical knowledge (Day 1994). This was strongly influenced later by the Cartesian theory which viewed the mind as something separate from the body. This brought out the concept of dualism, advocating thinking skills as separate from feeling and action (Cothingham, 1997).

Other philosophers began to appreciate thinking from an inherently different stance, arguing that the mind and body are interconnected and that knowledge is socially rather than individually constructed and thus thinking, feeling and action are intertwined (Hacker, 1992 Carifield, 1986). Consequently, the need to provide adequate way to help people to express themselves in dualism concept is reflection. Reflection has the potential for providing such a means as it potentially offers a key to unlocking the expression of something that previously we were not able to communicate.

Given the current attention paid to reflection in nursing curriculum in the United kingdom and over countries, this paper would focus on the need to introduce reflection in nursing education curriculum in Nigeria. What then is reflection?

\section{Reflection}

Various definitions exist for the term reflection. What is common in most of the definitions is that it is explorative of experience, analysis of feeling and of oneself to inform learning. There is also the element of critical theory where there is an assumption that reflection will involve a changed perspective, action, experimentation reviews and learning through one's experience. We would adopt Reed (1993,p.306) definition 
which does see reflection as a process of reviewing an experience of practice in order to describe, analyze, evaluate and to inform learning about practice. It involves opening one's practice for others to examine and require courage and open-mindedness as well as to take on board and act on-criticism (Dewey, 1933).

Reflection and reflective practice are terms that have become very familiar to contemporary nursing practice in the United Kingdom and other advanced countries. According to Burton (2000) they are terms that can engender a whole spectrum of reactions, ranging from positive enthusiasm to feelings of gross ambiguity and consternation. It is important to note that reflection used both as teaching and learning tools will develop nurses' intellectual capacity to contextualize knowledge to meet patients' needs. In addition reflection facilitates the integration of theory and practice and makes nurses critical thinkers' and doers' (Schon, 1991). If used reflectively, reflection can answer questions about the nature of nursing and can be used to generate nursing theory (Schon, 1987).The core idea underpinning reflective practice is that humans have the capacity to consider in introspective manner, the activities that they are engaged in and then moderate their future activities. In the next section we would examine types of reflection followed by the discussion as to what constitute nursing knowledge in order to conceptualize practice.

\section{Types Of Reflections}

Schon (1990) indentifies two types of reflection namely, reflection-in-action and reflection -on action. Reflection-in-action is where the competent practitioner uses knowledge, experience and judgment to guide decision in real life clinical situations as they are happening while reflection -on-action which happens after the experience enables learning about clinical practice and promotes development of such practice.

Reflection-in-action helps in the modification and development of ideas during practice (utilizing problem solving approach) while the latter being a congnitive post-mortem, looking back at past practice (Bolton, 2005). This enables the practitioner to analyze hunches and associated theories-in-use. Identifying the contributions of each to the particular practice experienced to the actual outcome enables those theories to be made explicit and then be analyzed critically.

In order to carry out reflective practice some skills have been identified by Atkin and Schutz (2009) as necessary for practice, these are;

1. Self-awareness

2. Description

3. Critical analysis

4. Synthesis

5. Evaluation,

A brief note on each is in order:

Self-awareness

To be self aware is to be conscious of one's character, including beliefs, values, qualities, strength and limitation. It also involves the social self, that which others influence and shape. This includes culture, education and socialization. Burnard (1992) distinguishes between the inner self, how one feels inside and the outer self, the aspects that other people see including appearance verbal and non-verbal behaviour. Self-awareness may be described as the foundation upon which reflective practice is built. It under pins the entire process of reflection because it enables people to see themselves in a particular situation and also to observe how they have influenced the situation and affected them. It has been noted that the use of self-awareness and personal knowledge have differentiated reflective learning from other types of mental activity like logical thinking (Bond, Keogh and Walker 1985).

\section{Description}

To describe something, whether it is a person, an object, a situation or an abstract concept or idea, is to state its characteristics or appearance without expressing a judgment in professional practice. Good descriptive abilities are necessary when communicating verbally with colleagues about patients and for writing clear and accurate patient progress. When using reflection-on-action, description is the skill with which you recollect the important events and features of your practice. Good description is about giving a clear and comprehensive account of a situation. The account could follow key elements:

Significant background factors

The events as they unfolded in the situation

What you were thinking at the time

How you were feeling at the time

The outcome of the situation.

Description enables someone who was not there to understand the situation from your positions. What is important here is to find the most appropriate words to express oneself, there is need to avoid the use of jargon and terminology which the reader and listener may not understand. To be able to describe events that 
have taken place in the past, nurses are advised to keep a diary that records and describes events in one's profession and practice which may therefore enhance one's descriptive abilities.

Critical analysis

Is a key skill for both reflective practice and academic study. Analysis involves the separation of a whole into its component parts. According to Atkins and Schutz (2009) critical analysis is to analyze something whether an object, a set of ideas or a situation. It is to undertake a detailed examination of the structure or constituent parts or elements or ask questions about them, in order to carefully understand their nature and how the parts relate to and influence each other. The term 'critical' introduces a further dimension to analysis in that, judgment is made about the strengths and weakness of the different parts, as well as of the whole.

Acknowledging and analyzing beliefs, values, and feelings are a fundamental and important part of reflection. If the outcome is to have a positive effect on professional learning practice and ultimately the quality of patient care. In reflective practice the skill of critical analysis involves;

Identifying and illuminating existing knowledge of relevance to the situation.

Exploring feelings about the situation and the influence of these

Identifying and challenging any assumptions you may have made. Synthesis

Imagining and exploring alternative course of action (Brokfiled, 1982).

Is the process or result of building up separate elements, especially ideas into a connected and coherent whole. It could be described as the opposite of analysis. Synthesis is about the artistry of professional practice and about being creative and also involves original thinking. At a fundamental level of practice, devising a patient care plan is an example of the synthesis of information from a variety of different sources.

In reflective practice, synthesis is the ability to integrate new knowledge, feelings or attitudes with previous knowledge, feelings or attitudes. This is important because it brings fresh insight or a new perspective on a situation and therefore to learn from it.

Is the ability to make judgment about the value of something. It entails a 'look back. Judgments are often made with reference to predefined criteria or standards. Evaluation is a high-level skill in both reflective practice and academic study. Evaluation is a personal process in which one examines oneself, frequently overtime. It is an important component of reflective practice and professional education.

Having discussed what is reflection and reflective skill it is necessary to examine what constitutes nursing knowledge and practice that is reflected upon. The next section would pay attention to nursing knowledge and nursing practice.

\section{Nursing knowledge and nursing practice.}

The drive towards learning from reflection in nursing relates to the nature of nursing knowledge and nursing practice. Most often nurses find it difficult to define what is it that constitutes nursing practice. In response to this "Activities of Living" model was developed ( Roper, Logan and Tierney 1980). The model was the first attempt by British nurses to develop a conceptual model for nursing and it has become widely used in Great Britain in a range of clinical and educational settings. According to Roper, Logan and Tierney (1980), nurses need knowledge concerning the physiology, social and psychological aspects of each of 12 activities of living and about the development progression along the lifespan.

The existence of nursing is for the provision of a nursing service to those who need, seek or are directed to nursing (Pearson, 1992, p.123). Jacox (1974) also suggested that practice or service delivery, is the beginning and end of nursing and that anything else which surrounds or cloaks practice is meaningless in comparison.

Having dealt with nursing practice, it is important to look at where nurses draw their knowledge of practice from on which they reflect. In order to begin to understand the complexities of nursing practice, we need to have an understanding of the knowledge nurses posses (Macleod, 1994). Although all nurses know nursing, but what they know and how they know may be different due to the unique experiences of each nurse and that nurses ability and desire to reflect upon experience (Pearson, 1992). What then is nursing knowledge?

The Oxford Advanced Learner's Dictionary (2010) defines knowledge as "information, skills and understanding that you have gained through education or experience". According to one sample of practitioners (May, Mulhall and Alexander 1996) nursing knowledge comes from a variety of sources. Patients and clients provide nurses with a wealth of knowledge which informs practice. Other sources include, initial training as student nurses, periods of continuing education and training following qualification and through one's own personal and professional development. These have a direct influence upon nursing knowledge. The development of nursing has certainly been influenced by other disciplines such as psychology, sociology, physiology and anatomy. 
In examining nursing knowledge, Carper's (1978) seminal work which talks about fundamental patterns of knowing would be adopted here. Carper (1978) concludes that the rationale for nursing practice has patterns, forms and structures that serves as horizons of expectations and exemplify characteristics ways of thinking about phenomena. This pays critical attention to the kinds of knowledge which are held to be of most value in the discipline of nursing. Carper (1978) identified four patterns of knowing; empirical, ethical, aesthetic and personal.

Empirical knowledge is the science of nursing, the knowledge that is systematically organized into general laws and theories for the purpose of describing, explaining and predicting phenomena of special concern to the discipline of nursing. Schultz and Meleis (1988) suggested that nurses use knowledge from other disciplines but through reflection and imagination evolve perspectives on that knowledge which are unique to nursing.

Esthetical knowledge is the art of nursing. It is concerned with the action of nursing and is often linked with discussions surrounding the art of nursing (Katinis, 1993; Johnson, 1994; as cited in Berragan 2001). This type of knowledge involves perception, understanding and empathy and acknowledges the value of everyday experience lived by individuals.

Ethical knowledge represents the moral component. It involves moral code which guides the ethical conduct of nursing and is based on the primary principle of obligation embodied in the concepts of service to people and respect for human life. Knowledge of morality in nursing goes beyond simply knowing the ethical codes of the disciplines. It includes all voluntary actions that are deliberate and subject to the judgment of right and wrong in a given situation.

Personal knowledge involves self-awareness and is subjective. Self-awareness impinges upon practice since one's understanding influences everything one does. Personal knowledge is very important to all areas of nursing practice and it is difficult to envisage the development of practice without this essential element. Having examined the sources of knowledge for reflection it is necessary to pay some attention to the benefits of reflection in nursing.

\section{Benefits Of Reflective Practice In Nursing} below;

Various benefits of reflective practice to nursing care have been identified. Some of these are listed

1. Reflective practice improves nurse practice if the nurse takes time to reflect on different parts of care rendered and on which aspects of the care to be improved. It would also help to indicate how problems which arise could be solved, and would no doubt help to improve nursing practice.

2. Learning from reflective practice: There is a good range of evidence that purposeful reflective practice helps 'deep' learning take place and for the nurse, it will help to make connections between different aspects of one's care and what goes on around one's nursing practice.

3. Enhances problem solving skills: Through critical thinking on nursing care, one may tend to concentrate on issues which arise. By carefully and honestly considering and analysis these to find solutions.

4. Becoming a critical thinker: Critical thinking is about 'thinking well' and 'taking charge' of one's own thinking (Elder and Paul, 1994). Reflective practice will help one recognize and adjust what one thinks to take account of changes in circumstances and by doing that help one to be better equipped to find solutions which work.

5. Making decisions: As nurses reflect on their practice, they will find the need to make decision about what to do or not to do next. They may well have number of choices which they need to weigh up and deciding which one to take can be difficult. If nurses are regularly going to come across the need to make decisions, the results of reflective practice will help nurses to make those decisions in a more informed, thoughtful and objective manner.

6. Improving nurses organizational skills: Nurses will notice as different sections of nursing progresses that the benefits of reflective practice reaches every aspect of one's professional work as a nurse. If one is thinking carefully about what one is doing, identifying possible actions and choices, trying out solutions, adjusting what one does to take account of the results, this involves a good deal of organization. By breaking down issues and problems into steps or stages one will get better organizing one's time and to concentrate on the important, 'solution-focused' actions.

In spite of the benefits listed in the foregoing section reflective practice has not been adopted in Nigeria. What then are the obstacles to the adoption of reflective practice in Nigeria.

\section{Obstacles to Reflective Practice in Nigeria.}

The obstacles to reflective practice in nursing in Nigeria include the following;

\section{Absence of Reflection and Reflective Practice in Nursing Curriculum:}


Up till this point in time, nursing curriculum does not include reflective practice in Nigeria. This is a major obstacle to the teaching of reflective practice in nursing schools in the country. Since it is not in the curriculum, there is no way it can be taught in nursing programmes.

2. Absence of Mentor/Supervisor:

Closely related to the above is the absence of mentors/supervisors in reflective practice in Nigeria. A good mentor/supervisor will help practitioners to stay in charge of what they reveal in their verbal reflection. Mentor/supervisor has a key role to play in encouraging and challenging reflection with their students. This is of course dependent on a positive relationship where trust and communication is fostered. As important as mentors/supervisors are, they serve as "sounding boards" for ideas occasionally giving an expert viewpoint, supporting a student who is emotionally affected by a practice incident or challenging the student to think through ideas and thought so as to stimulate a critical dialogue.

\section{Lack of Lecturer and Clinical Instructors:}

In view of the fact that reflective practice is not in nursing school programmes, there are no lecturers and clinical instructors with requisite skills to teach it. There is need for lecturers and clinical instructors to be prepared and must have acquired some experience of reflection and be able to offer students a balance of support and challenge. They also need to have experience in the student field of experience so that they can understand contextual issues that influence student experiences.

\section{Way Forward}

What then are the necessary steps to be taken to introduce reflective practice into the nursing curriculum in Nigeria. The first step is the inclusion of reflection in nursing curriculum in Nigeria. Reflective practice has been in the United Kingdom nursing curriculum since the entrance of nursing into the university after the Second World War.

In order to include reflective practice into the nursing curriculum in Nigeria, there should be conferences, workshops and short courses for the teaching staff in nursing programmes, reflective skills would be introduced gradually, starting with skills of self-awareness and moving through those of description, critical analysis and evaluation. Heath (1998) asserted that through those stages novies will be overwhelmed by the new experiences to which they are exposed. Efforts should be made to send new and old staff for training in countries that have been implementing reflective practice in their nursing programmes for years.

\section{Conclusion}

This paper has tried to examine the concept of reflective practice in nursing practice. In particular it examined the concept of reflection, the necessary skills needed to carry out reflective practice successfully, the impediments to reflective practice in Nigeria at this point in time and the way forward.

The impact of reflection on nursing education cannot be overemphasized because it is a vehicle for learning which has led many nurse educators to develop an interest in reflective practice. This interest has been demonstrated in a number of ways;

Introduction of reflection into course curricula.

- Evidence that reflection-on-practice is used in the formal assessment of students' progress towards nursing qualifications.

With the evidence that reflection can really inform nursing practice, it has helped nurses to think critically before, after and in practice with subsequent improvements in the care that patients receive. It's plausibility as an essential skill for the profession to acquire becomes evident.

\section{References}

[1]. Atkins S. and Schutz S. (2009) (as cited in Bulman C. and Schutz S. 2009) Reflective Practice in Nursing : $4^{\text {th }}$ Edition. Blackwell Publishing Ltd.

[2]. Bernett, R. (1992) Improving Higher Education. Society for Research into Higher Education. Open University Press. London.

[3]. Bond,D.Keogh, R. and Walker, D (1985) Promoting Reflection in Learning. A Model in Reflection Turning Experience into Learning (Eds) Bond, R, Keogh R. and Walker, D) pp. 18-39.

[4]. Bookfleld ,S.D (1987) Developing Critical Thinkers: Challenging Adults To Explore Alternative Ways Of Thinking And Acting. Open University Press. Milton Keynes.

[5]. Boton, G. (2005) Reflective Practice: Writing and Professional Development. Sage London.

[6]. Burnard, P. (1992) Know Yourself, Self-awareners Activities for Nurses. Scutari Press. London.

[7]. Burton, A. j (2000) Reflection: Nursing's Practice and Education Panacea? Journal of Advanced Nursing, 31(5) 1009-1017.

[8]. Carper, B.A. (1986) Fundamental Patterns of Knowing in Nursing, Advances in Nursing Science Practice Orientated Theory 1(1) 13-23.

[9]. Canfield, J.V. (1986) The Philosophy of Wittgenstein. Volume 12. Person Garland Publishing. New York.

[10]. Cottingham, J. (1997) Descartes' Philosophy of Mind. Phoenix, London.

[11]. Day, J.M. (1994) Plato's Meno in Focus Routledge, London.

[12]. Dewey, J. (1933) How We Think. A Restatement of the Relation of Reflective Thinking to the Educative Process. Dc Health Boston.

[13]. Hacker, P.M.S. (1997) Wittigenstein, Phenix, Londan. 
[14]. Jacox, A. (1974) Theory Construction in Nursing: An Overview. Nursing Research 23(1), 4-13.

[15]. John, J.C.(1994) (as Cited in Beranaan (2001)) A Discussion Of The Strengths And Weakness Of "Reflection" In Nursing Practice And Education: Journal of Clinical Nursing 10, 278-283.

[16]. Katim, I. (1993) Nursing as Aesthetic Experience and the Motion of Practice. Scholarly Enquiry for Nursing Practice 7(4) 269-272.

[17]. Leira, A (1994 June). Concepts of Caring, Loving, Thinking and Doing, Social Serview Review. 185-201.

[18]. Le May, A. Mulhall A. and Alexander, C. (1996) Implementing research into Practice. The Research Culture, Myth or Reality? Paper Presented at the Royal College of Nursing Annual Research Conference New Castle.

[19]. Macleod, M. (1994) It's the little things that counts the hidden complexity of everyday clinical nursing practice. Journal of clinical nursing 3, 361-368.

[20]. Oxford Advanced Leaner's Dictionary (2010). Oxford University Press, Oxford United Kingdom.

[21]. Pearson, A. Robert, K. and Vaughan B. (1992) Emerging paradigms in nursing. In knowledge for nursing practice. Butterworth heinemann oxford, pp 213-226.

[22]. Reid, B. (1993) ‘But Were Doing It Already' Exploring A Response To The Concept Of Reflective Practice in Order to Improve its Facilitation. Nursing Education Today 13, 305-309.

[23]. Reed.B. and Ground, I (1997) Philosophy For Nursing. Arnold, London.

[24]. Rooper, N. Logan, W. and Tierney A. (1980) The Element of Nursing. Churchill Livingstone, Edinburgh.

[25]. Schon, D. (1991) The Reflective Practioner 2nd (ed) Jossey-Bass San Fransciso.

[26]. Schultz C. and Meleis D. (1988) Nursing Epistemology: Traditions, Insights, Questions. Journal of Nursing Scholarship 20 (4) 217 221.

[27]. Schon D. (1990) (as Cited in Johnson, C. and Bird, J). Teach Reflective Practice. School of Postgraduate Medical Education. Wales College Medicine, Cardiff, University Health Park, Cardiff Cf 14, 4 xN.

[28]. Taylor, R.L. and Watson, J. 1989. They Shall Not Hurt: Human Carrying and Suffering.Boulder: Colorado Associated University Press. 